\title{
A Novel Over-The-Scope Clip (OTSC) For the Treatment of Severe Non-Variceal Upper GI-Bleeding: An Alternative to Classic Hemostatic Techniques?
}

\author{
Wedi $\mathrm{E}^{*}$, Jung $\mathrm{C}$ and Allrath $\mathrm{T}$ \\ Department of Gastroenterology and Gastrointestinal Oncology, University Medical Centre Goettingen, Germany
}

Submission: October 26, 2017; Published: November 28, 2017

"Corresponding author: Wedi E, Interdisciplinary Endoscopy, Department of Gastroenterology and GI Oncology, University Medical Centre Goettingen, Georg-August-University, D-37075 Goettingen, Germany, Email: edriswedi@gmail.com

\begin{abstract}
Gastrointestinal bleeding is a frequent endoscopic emergency. The mortality rate, due to non-variceal upper gastrointestinal bleeding (NVUGB), remains despite technical advances between 5-10\%. Conventional endoscopic treatment includes through the scope clips (TTSC), injection therapy and thermal therapy. The over-the-scope-clip (OTSC) is a novel endoscopic device, that overcomes limitations of standard clips and achieves a more efficient and reliable haemostasis in non-variceal upper gastrointestinal bleeding (NVUGIB). His review article gives an overview of the recently published data on this topic and discusses future perspectives in GI-bleeding management.
\end{abstract}

Keywords: Endoscopy; Non-variceal upper gi bleeding; Over-the-scope clip; OTSC

\section{Introduction}

Gastrointestinal bleeding is frequent in clinical practice and one of the main indications for emergency endoscopy. The mortality rate due to non-variceal upper gastrointestinal bleeding (NVUGB) lies between 5-10\% [1]. Conventional endoscopic treatment for NVUGB includes through the scope clips (TTSC), injection therapy and thermal therapy. It has been shown, that a combination of two endoscopic techniques is superior to an individual technique alone and is therefore recommended [2]. Nevertheless, these hemostatic methods have their limitations and can fail in complex bleeding situations, such as fibrotic ulcer ground, vessel diameter $>2 \mathrm{~mm}$ and ulcer localization difficult to access. The over-the-scope-clip (OTSC; Ovesco Endoscopy AG, Tuebingen, Germany) is a new promising endoscopic device, which could overcome these limitations. It consists of super-elastic Nitinol and has the shape of a bear trap mounted on a transparent cap (Figure 1a) [3]. The mechanism of action is comparable to the application mechanism of varicealband ligation devices. After clip application the tissue is kept vital based on a pre-defined distance between the clip teeth promoting sufficient vascular perfusion [3]. Pre-clinical experiments were performed in porcine models for NOTES procedures (natural orifice translumenal endoscopic surgery), defect closure for targeted perforations and endoscopic full-thickness resection [4-12]. For the treatment of NVUGB, only limited data has been published so far. Therefore the objective of this review is to give a brief insight of recently published studies on this topic, which we have found through a systematic search of the medical database Pubmed.

\section{Results and Discussion}

A total of 15 clinical research articleswere identified. The examined clinical studies comprised case series and clinical singlearm studies (Table 1). Krischniak et al. [8] reported in 2007 as one of the first authors in a retrospective clinical trial on eleven patients, the application of OTSC as first-line therapy with a clinical success rate of $100 \%$. No complications were reported after a follow-up of four weeks. In the past, there has been significant improvement in the endoscopic treatment of NVUGIB due to better clipping systems and new substances for topical hemostasis, like the hemospray. Despite these advances, the risk of re-bleeding still remains high, around $20 \%$. The mortality rate in this patient group lies between $10-36 \%$ [9-11]. The OTSC can overcome the limitations of standard TTS clips and achieve a more efficient haemostasis. This literature review confirms that by using OTSC in high-risk patients primary 
hemostasis can be achieved in 77.8-100\% (Table 1). Recently published data show higher therapeutic success rates using the OTSC as first-line therapy for gastrointestinal bleeding and for prevention of re-bleeding in high-risk patients [12]. Manno et al. [13] published their experience in 40 cases, where they used the OTSC as first-line therapy in NVUGIB with a technical success and hemostasis in $100 \%$ of the treated patients. Another Italien Study reported about 30 patients who were treated with bleeding lesions with primary hemostasis in 97\% [14]. To date Richter-Schrag et al. [12] has published the largest patient cohort $(n=93)$ with upper and lower GI bleeding and they could show for the first time that firstline treatment with the OTSC might be the best predictor preventing rebleeding compared to second-line therapy with OTSC after failure of another technique. They concluded that the type of treatment determines the success of primary hemostasis or primary failure. Our own clinical experience show, that after efficient application of the OTSC with successful hemostasis in patients on anticoagulation or antiplatelet therapy, this can be resumed within 24-48 hours after OTSC application. This is a significant advantage of this system. Nevertheless, these patients will remain a challenge in managing bleeding versus risk of stopping anticoagulation. Up to now the published data are promising, but retrospective nature. Prospective randomized trials of emergency situations are difficult to conduct and therefore data is limited in this field [14-26].

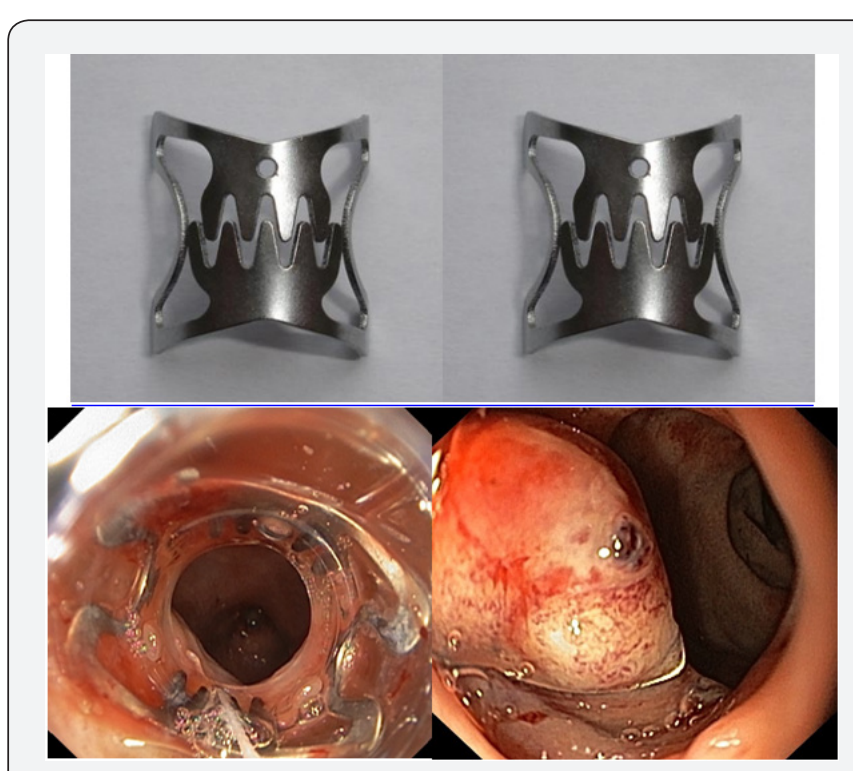

Figure 1: a/b: OTSC in unloaded form and the OTSC set (applicator cap with clip, thread retriever, thread and hand wheel). c/d: A case of ulcer bleeding in the duodenal bulb (Forrest Ila) in a patient who had a pulmonary embolism 4 weeks before this bleeding episode occurred and was full-anticoagulated with warfarin. On this account the patient was treated with a $12 \mathrm{~mm}$ OTSC Typa effectively.

Table 1: Literature overview.

\begin{tabular}{|c|c|c|c|c|c|c|}
\hline & Study Design & $\mathbf{N}$ & Primary Success \% & Follow Up Mean (Month) & Rebleeding No. & UGIB/LGIB No. \\
\hline Richter-Schrag [12] & Single center Retrospective & 93 & 88 & - & 16 & $63 / 30$ \\
\hline Wedi [3] & Single center Retrospective & 44 & 85.4 & - & 6 & $41 / 3$ \\
\hline Manno [13] & $\begin{array}{c}\text { Single center } \\
\text { RetrospectiveRetrospective }\end{array}$ & 40 & 100 & 1 & - & $40 / 0$ \\
\hline Manta [14] & Multicenter Retrospective & 30 & 97 & 1 & 2 & $23 / 7$ \\
\hline Kirschniak [15] & Single center Retrospective & 27 & 100 & 0.13 & 2 & 15-Dec \\
\hline Skinner [16] & Single center Retrospective & 12 & 100 & 1 & 2 & 12 \\
\hline Chan SM [17] & Single center Retrospective & 9 & 100 & 2 & 2 & 9 \\
\hline Nishiyma [18] & Single center Retrospective & 9 & 77.8 & 2.2 & 2 & 1-Aug \\
\hline Baron [19] & Multicenter Retrospective & 7 & 100 & 1 & 0 & 1-Jun \\
\hline Albert [20] & Single center Retrospective & 7 & 100 & 1 & 3 & 1-Jun \\
\hline Repici [21] & Single center Retrospective & 7 & 100 & 3 & 0 & 4-Mar \\
\hline Mönkem üller [22] & Multicenter Retrospective & 6 & 100 & 10 & 0 & 6 \\
\hline Alcaide [23] & Single center Retrospective & 2 & 100 & - & - & 1-Jan \\
\hline Jayaraman [24] & Single center Retrospective & 2 & 100 & 2.9 & 0 & $0 / 2$ \\
\hline Sulz [25] & Single center Retrospective & 1 & 100 & - & 0 & 1 \\
\hline
\end{tabular}




\section{Conclusion}

In conclusion, this short literature review demonstrates that OTSC application is a successful treatment in patients with complex lesions for the treatment of severe NVUGIB. Prospective studies are necessary to demonstrate the superiority of OTSC in comparison to classic hemostatic techniques.

\section{References}

1. Barkun AN, Bardou M, Kuipers EJ, Sung J, Hunt RH, et al. (2010) International consensus recommendations on the management of patients with nonvariceal upper gastrointestinal bleeding. Ann Intern Med 152(2): 101-113.

2. Vergara M, Calvet X, Gisbert JP (2014) Epinephrine injection versus epinephrine injection and a second endoscopic method in high risk bleeding ulcers. Cochrane Database Syst Rev (10): CD005584.

3. Wedi E, Gonzalez S, Menke D, Kruse E, Matthes K, et al. (2016) One hundred and one over-the-scope-clip applications for severe gastrointestinal bleeding, leaks and fistulas. World J Gastroenterol 22(5): 1844-1853.

4. Schurr MO, Hartmann C, Ho CN, Fleisch C, Kirschniak A (2008) An over-the-scope clip (OTSC) system for closure of iatrogenic colon perforations: results of an experimental survival study in pigs. Endoscopy 40(7): 584-588.

5. Naegel A, Bolz J, Zopf Y, Matthes K, Mueller B, et al. (2012) Hemodynamic efficacy of the over-the-scope clip in an established porcine cadaveric model for spurting bleeding. Gastrointest Endosc 75(1): 152-159.

6. von Renteln D, Schmidt A, Vassiliou MC, Rudolph HU, Gieselmann M, et al. (2009) Endoscopic closure of large colonic perforations using an over-the-scope clip: a randomized controlled porcine study. Endoscopy 41(6): 481-486.

7. von Renteln D, Schiefke I, Fuchs KH, Raczynski S, Philipper M, et al. (2009) Endoscopic full-thickness plication for the treatment of gastroesophageal reflux disease using multiple Plicator implants: 12-month multicenter study results. Surg Endosc 23(8): 1866-1875.

8. Kirschniak A, Kratt T, Stúker D, Braun A, Schurr MO, et al. (2007) A new endoscopic over-the-scope clip system for treatment of lesions and bleeding in the GI tract: first clinical experiences. Gastrointest Endosc 66(1): 162-167.

9. Lewis JD, Bilker WB, Brensinger C, Farrar JT, Strom BL (2002) Hospitalization and mortality rates from peptic ulcer disease and GI bleeding in the 1990s: relationship to sales of nonsteroidal anti-inflammatory drugs and acid suppression medications. Am Gastroenterol 97(10): 2540-2549.

10. Martins NB, Wassef W (2006) Upper gastrointestinal bleeding. Curr Opin Gastroenterol 22(6): 612-619.

11. Esrailian E, Gralnek IM (2005) Nonvariceal upper gastrointestinal bleeding: epidemiology and diagnosis. Gastroenterol Clin North Am 34(4): 589-605

12. Richter-Schrag HJ, Glatz T, Walker C, Fischer A, Thimme R (2016) First-line endoscopic treatment with over-the-scope clips significantly improves the primary failure and rebleeding rates in high-risk gastrointestinal bleeding: A single-center experience with 100 cases. World J Gastroenterol 22(41): 9162-9171.

13. Manno M, Mangiafico S, Caruso A, Barbera C, Bertani H, et al. (2015) First-line endoscopic treatment with OTSC in patients with high-risk non-variceal upper gastrointestinal bleeding: preliminary experience in 40 cases. Surg Endosc 30(5): 2026-2029.

14. Richter-Schrag H (2016) First-line endoscopic treatment with over-thescope clips significantly improves the primary failure and rebleeding rates in high-risk gastrointestinal bleeding: A single-center experience with 100 cases. World J Gastroenterol 22(41): 9162-9171

15. Manta R, Galloro G, Mangiavillano B, Conigliaro R, Pasquale L, et al. (2013) Over-the-scope clip (OTSC) represents an effective endoscopic treatment for acute GI bleeding after failure of conventional techniques. Surg Endosc 27(9): 3162-3164.

16. Kirschniak A, Subotova N, Zieker D, Königsrainer A, Kratt T, et al. (2011) The Over-The-Scope Clip (OTSC) for the treatment of gastrointestinal bleeding, perforations, and fistulas. Surg Endosc 25(9): 2901-2905.

17. Skinner M, Gutierrez JP, Neumann H, Wilcox CM, Burski C, et al. (2014) Over-the-scope clip placement is effective rescue therapy for severe acute upper gastrointestinal bleeding. EndoscInt Open 2(1): E37-E40.

18. Chan SM, Chiu PW, Teoh AY, Lau JY (2014) Use of the Over-The-Scope Clip for treatment of refractory upper gastrointestinal bleeding: a case series. Endoscopy 46(5): 428-431.

19. Nishiyama N, Mori H, Kobara H, Rafiq K, Fujihara S, et al. (2013) Efficacy and safety of over-the-scope clip: including complications after endoscopic submucosal dissection. World J Gastroenterol 19(18): 2752-2760.

20. Baron TH, Song LM, Ross A, Tokar JL, Irani S, et al. (2012) Use of an over-the-scope clipping device: multicenter retrospective results of the first U.S. experience (with videos). Gastrointest Endosc 76(1): 202-208.

21. Albert JG, Friedrich-Rust M, Woeste G, Strey C, Bechstein WO, et al. (2011) Benefit of a clipping device in use in intestinal bleeding and intestinal leakage. Gastrointest Endosc 74(2): 389-397.

22. Repici A, Arezzo A, De Caro G, Morino M, Pagano N, et al. (2009) Clinical experience with a new endoscopic over-the-scope clip system for use in the GI tract. Dig Liver Dis 41(6): 406-410.

23. Monkemuller K, Toshniwal J, Zabielski M, Vormbrock K, Neumann H, et al. (2012) Utility of the "bear claw", or over-the-scope clip (OTSC) system, to provide endoscopic hemostasis for bleeding posterior duodenal ulcers. Endoscopy 44(Suppl 2): E412-E413.

24. Alcaide N, Peñas-Herrero I, Sancho-del-Val L, Ruiz-Zorrilla R, Jesús B, et al. (2014) Ovesco system for treatment of postpolypectomy bleeding after failure of conventional treatment. Rev Esp Enferm Dig 106(1): 55-58.

25. Jayaraman V, Hammerle C, Lo SK, Jamil L, Gupta K, et al. (2013) Clinical Application and Outcomes of Over the Scope Clip Device: Initial US Experience in Humans. Diagn Ther Endosc 2013: 381873.

26. Sulz MC, Bertolini R, Frei R, Semadeni GM, Borovicka J, et al. (2014) Multipurpose use of the over-the-scope-clip system ("Bear claw") in the gastrointestinal tract: Swiss experience in a tertiary center. World J Gastroenterol 20(43): 16287-16292. 
